Para enlazar con este artículo / To link to this article:

http://dx.doi.org/10.14198/fem.2018.31.07

Para citar este artículo / To cite this article:

Romero Morales, Yasmina. «La narrativa colonial española sobre Marruecos como fuente para el estudio de la mora-bestia: deshumanización y monstruosidad». En Feminismo/s, 31 (junio 2018): 143-166. Dosier monográfico: Sexo y bienestar. Mujeres y diversidad, coords. Carmen Mañas Viejo y Alicia Martínez Sanz, DOI: $10.14198 / \mathrm{fem} .2018 .31 .07$

\title{
LA NARRATIVA COLONIAL ESPAÑOLA SOBRE MARRUECOS COMO FUENTE PARA EL ESTUDIO DE LA MORA-BESTIA: DESHUMANIZACIÓN Y MONSTRUOSIDAD
}

\section{THE SPANISH COLONIAL NARRATIVE ABOUT MOROCCO AS A SOURCE FOR THE STUDY OF THE MOOR-WOMAN- BEAST: ANIMALIZATION AND MONSTRUOSITY}

\author{
Yasmina ROMERO MORALES \\ Universidad de la Laguna \\ orcid.org/0000-0003-0255-5782
}

\section{Resumen}

El objetivo de estas páginas es estudiar la representación de un personaje secundario, pero de aparición frecuente en la narrativa española de colonias publicada durante el siglo XX y a la que se ha decidido denominar mora-bestia. Esta mora-bestia es un tipo de «otra» marroquí que siempre ha vivido en el campo, a la que suele describirse como bestia de carga y que sufre diferentes procesos deshumanizadores como la animalización, naturalización, cosificación y monstruosificación. Una representación islamófoba que, bajo pretextos civilizadores que sirven de coartada para aplicar políticas coloniales y/o hegemónicas, fomenta la alterización y deshumanización de las verdaderas mujeres marroquíes, aquellas plurales y diversas que habitan en el Marruecos factual.

Palabras clave: Narrativa colonial española, alteridad, Marruecos, escritoras. 


\begin{abstract}
The objective of these pages is to study the representation of a secondary character, but one that appears frequently in the Spanish colonial narrative published during the 20th century and which has been decided to name moor-woman-beast. This moorwoman-beast is a type of «other» Moroccan who has always lived in the countryside, which is often described as a beast of burden and suffers different dehumanizing processes such as animalization, naturalization, reification and monstruosification. A islamophobic representation that, under civilizing pretexts that serve as an alibi for applying colonial and/or hegemonic policies, encourages the otherisation and dehumanization of the true Moroccan women, those women plural and diverse that live in the factual Morocco.
\end{abstract}

Keywords: Spanish Colonial Narrative, Otherness, Morocco, Women Writers.

\title{
1. INTRODUCCIÓN
}

La pérdida de las últimas colonias ultramarinas -Cuba, Puerto Rico y Filipinas- hizo que España redirigiera sus intereses hacia un nuevo horizonte colonial, fue entonces cuando puso sus miras estratégicas en África. Sin embargo, el álbum de fotografías de la historia compartida entre España y Marruecos durante el pasado siglo XX, exactamente hasta 1956 con la independencia de Marruecos, ha sido una ida y venida de instantáneas de enfrentamientos que tuvieron un gran coste económico y en vidas humanas en ambos bandos. Con todo, y a pesar de estos conflictos, España ni siquiera vio sus objetivos plenamente cumplidos con la implantación en el norte de África del Protectorado franco-español en Marruecos (1912-56), en la medida en que se le reconocieron ciertos derechos e intereses en una zona pequeña del norte de Marruecos -aproximadamente el 4\% de todo el territorio del país (Mateo Dieste, La hermandad hispano-marroquí 58).-Se convirtió así, en palabras de María Rosa de Madariaga, en «subcontratista o subarrendataria de Francia» (El protectorado español 172).

Aun así, esta presencia española en Marruecos hizo que muchas familias españolas tuvieran interés por lo que allí acontecía. Esta es la razón por la que centenas de escritores y de escritoras españoles, como resultado de la experiencia colonial de España en el norte de África, publicaran sus textos durante el pasado siglo $\mathrm{XX}$, una producción que ha comprendido todos los

Feminismo/s 31, junio 2018, pp. 143-166 
géneros literarios, aunque esencialmente hayan sido el libro de viaje, la novela y el relato los más repetidos.

En esta investigación se pone el foco de atención en esas novelas y relatos de ficción. Hay más de doscientas que, durante la pasada centuria, escogieron Marruecos como escenario literario (López García; Carrasco González) pero no dejan de publicarse actualmente más, como la aplaudida El tiempo entre costuras (2009) de María Dueñas o la finalista del Premio Planeta Niebla en Tánger (2017) de Cristina López Barrio. Una producción literaria que puede entenderse en sí misma como un indiscutible género de colonias, esto es, aquella «manera de narrar sobre países alejados sin pertenecer al pueblo natural de ellos y con un sentimiento o mentalidad mayor o menor, de alteridad» (Carrasco González 9).

Del ingente volumen de novelas y relatos de ficción propios del género de colonias español publicados durante el pasado siglo XX y del que se tiene constancia, esta investigación ha escogido como fuentes primarias sólo las escritas por mujeres, un conjunto de 59 textos que rescata del olvido -hay que reconocer que muchas de ellas lo estaban-, a 19 autoras ${ }^{1}$. Optar por escritoras únicamente no es en ningún caso una prerrogativa adoptada ni, tampoco, ambición alguna de recluirlas una vez más en su propia situación de marginación por motivo de sexo, sobre todo cuando el estudio pormenorizado de su narrativa evidencia que perpetúan el mismo discurso sobre la alteridad marroquí que los autores españoles (Romero Morales). Ahora bien, el canon literario se dispone de manera sexista -también clasista, es innegable, pero me interesa en este punto enfatizar fundamentalmente la discriminación por motivo de género- y, de ahí que estas páginas patrocinen lo que podría denominarse una reivindicación literaria, y es que «en una sociedad machista que discrimina a las escritoras precisamente porque son mujeres es fácil justificar el estudiarlas como grupo aparte» (Moi 91).

Una lectura atenta de este género de colonias demuestra que se desarrolla, principalmente, en espacio urbano y, contagiado de la realidad factual del otro

1. Carmen Martel, Concha López Sarasúa, Encarna Cabello, Marisa Villardefrancos, Regina Flavio, Concha Linares-Becerra, Mari Paz Estévez de Castro, Carmen de Burgos, María Charles, Carmen Martín de la Escalera, María Teresa de Jadraque, María Viñuelas, Blanca Ibáñez Blanco, Josefina María Rívas, Rosa de Aramburu, Margarita Astray Reguera, Rosa María Aranda, Carmen Nonell y Dora Bacaicoa. 
lado del Mediterráneo, los personajes femeninos imaginados que más visitan sus páginas son aquellos cubiertos por sus ropas de pies a cabeza. Una presencia oculta que causa tanta frustración que las fuentes tienen a bien crear su contrapunto, una «otra» marroquí sensual, cubierta de gasas y encerrada en el harén. Sin embargo, hay otro personaje frecuente que, aún de menor alcance narrativo, completa en mayor medida el retrato femenino de la otredad y es al que se dedicarán las próximas páginas: la mora-bestia . Un tipo de «otra» marroquí que siempre ha vivido en el campo, a la que suele describirse como bestia de carga y que sufre diferentes procesos deshumanizadores como la animalización, naturalización, cosificación y monstruosificación.

La hipótesis de partida es que la cultura universal no ha codificado en igualdad de condiciones a los hombres y a las mujeres. El imaginario social ha respondido a dogmas patriarcales que han naturalizado las desigualdades y que ha funcionado, en sí mismo, como una forma de violencia epistémica de carácter androcéntrico, pero como veremos en este trabajo, también de tipo colonial e imperialista. Esta aproximación aspira a hacer una contribución al estudio de la manera en que la narrativa colonial de tema marroquí, concretamente la del siglo XX y sólo escrita por mujeres, ha colaborado en el mantenimiento de ciertos tópicos, estereotipos y atributos negativos vinculados con la identidad normativa de la mujer de contextos árabe-islámicos, en particular, de la marroquí. Consideramos que únicamente el conocimiento mutuo es garantía fiable para mantener unas relaciones basadas en el respeto y la cooperación, hecho que beneficia a ambas orillas de El Estrecho de Gibraltar, sobre todo teniendo en cuenta que la interdependencia de ambos escenarios es una realidad innegable y no debiera estar sustentada en esencialistas imaginarios coloniales. Las próximas páginas pretenden colaborar en la desarticulación de estos prejuicios y estereotipos, sobre todo, en torno a la nociva imagen de la mora-bestia. Una representación islamófoba que, desde las primeras obras que denunciaron la situación de la mujer en Marruecos -como la del diplomático Felipe Ovilo y Canales, La mujer marroquí. Estudio social (1881)- encontró este filón demagógico para justificar la necesidad de llevar el progreso al país.

2. De aquí en adelante se utilizará el término moro/a como denotación léxica, ya que es el término más usado por las autoras estudiadas para designar a la población autóctona. En ningún momento está utilizado de manera irrespetuosa o peyorativa.

Feminismo/s 31, junio 2018, pp. 143-166 
Fue de esta manera como los pretextos civilizadores sirvieron de coartada para aplicar políticas coloniales y/o hegemónicas, y fomentaron la alterización y deshumanización de las verdaderas mujeres marroquíes.

Finalmente, por consiguiente, la metodología adoptada está cimentada sobre los principios vehiculares de la perspectiva de género, los estudios culturales que evidencian que la propia organización de la cultura es jerárquica y está íntimamente vinculada a las estructuras de poder (Hall, The Two Paradigms; Hall, Questions of Cultural Identity); y, finalmente, las teorías postcoloniales adoptadas a través de dos de sus autores más representativos: Edward W. Said y Gayatri Ch. Spivak. Aproximaciones, todas ellas, profundamente comprometidas y políticas que tienen la particularidad de hacer uso de una lectura ideológica de la cultura al mismo tiempo que, como descubriera Culler, tienen en común querer demostrar que lo que damos «como de sentido común es, de hecho, una construcción histórica» (15).

\section{LA MORA-BESTIA EN EL CAMPO. DE CÓMO LA «OTRA»SE CONVIRTIÓ EN MONSTRUO}

Los 59 textos analizados forman parte de una selección documental eminentemente urbana. Sin embargo, en algunas ocasiones las tramas se desplazan al campo y es ahí, donde aparece la mora-bestia. En las novelas se insiste en que es un tipo de «otra» ${ }^{3}$ marroquí que siempre ha vivido en el campo y que, por ello, su vista está «acostumbrada a no encontrar más límites que la tierra y el cielo» (Bacaicoa 91). Hablar de la mora-bestia suele ser sinónimo en estos textos de rifeñas o bereberes, pero en esta narrativa lo normal es que

3. Denominar a este personaje femenino marroquí «otra», a pesar de que utilizara esta categoría antes Simone de Beauvoir en El segundo sexo (1949), parte principalmente de una corriente posterior, nacida en los años 80 y basada en las aportaciones de Antonio Gramsci: los denominados Subaltern Studies, estudios de la subalternidad o subalternos. Esta corriente de pensamiento, incluida entre las teorías postcoloniales, ha servido para denunciar la condición específica de déficit de poder y, en consecuencia, de sumisión, de grupos minoritarios, tales como mujeres, negros, gays, lesbianas, etc. En este caso concreto, nos referimos a la mora-bestia, como «otra», entendiendo que esta es considerada en estas novelas y relatos como subalterna, esto es, inferior, tanto en lo que afecta a su posición o categoría como, también, a su colocación por debajo en términos culturales.

Feminismo/s 31, junio 2018, pp. 143-166 
las autoras no tengan una denominación clara de términos ${ }^{4}$, así que en este trabajo se considerará mora-bestia, de modo inclusivo y como categorización propia, a aquel personaje femenino que no habita en las ciudades. En este sentido, la denominación mora-bestia viene motivada por el uso que se le da en estas ficciones a la «otra» marroquí como bestia de carga:

No son mártires, porque no comprenden su situación y apenas tienen noticia de que en el resto de la tierra ocurra algo muy diferente. A su modo se sienten felices con las tradicionales costumbres de un pueblo que no desea deshacerse de lo que los años han acumulado sobre las frágiles espaldas femeninas. (Aranda 162-3)

En efecto, la «otra» marroquí en el campo no difiere de un animal al que se unce con un buey o un asno para completar el arado y así labrar el campo. De ahí la desesperación de algunos personajes masculinos, que acuden al médico con su esposa enferma: «no por el afecto que hacía ella sentía, sino porque, muy pobre, no podía comprarse otra; y, muerta aquélla, ¿a quién iba a enganchar con el mulo al arado?» (Astray Reguera 7-8).

La mora-bestia, al igual que un animal forzado a trabajar en la realización de las labores agrícolas, es la que surca la tierra uncida a un yugo, «una criatura primitiva, embrutecida por el trabajo» (Martín de la Escalera 226), «dedicadas a los trabajos más rudos» (De Burgos 211), una «campesina trabajada y rugosa, como tantas había visto en el campo, con todo un estigma de trabajos y sufrimientos impreso en el rostro» (Villardefrancos 28) que se dedican a las rudas faenas agrícolas «desde que pudieron atar una gavilla y sostener una hoz» (Flavio 39).

En la misma línea de animal de carga y transporte, la mora-bestia es también la que traslada sobre sus espaldas pesados fajos de leña:

Sus pies se hundían en el polvo del camino. Eran unos pies toscos, agrietados, como trozos de barro mal moldeado, como tallados en vieja madera seca. Eran unos pies que parecían hechos de la tierra misma. (Bacaicoa 87)

4. De los personajes femeninos locales se dice que son moras, árabes, musulmanas, bereberes, indígenas, rifeñas, sarracenas, beduinas, mahometanas o, simplemente, marroquíes. Una amplia gama de términos que apunta a categorías etnolingüísticas, religiosas o de procedencia, totalmente diferentes y que, por tanto, designan a distintos tipos humanos pero que se utilizan casi de manera indistinta. Se ha trabajado este aspecto en Romero Morales (2018). 
Leamos otro ejemplo más donde no sólo se asegura que ellas cargan la leña, sino que también lo hacen para el descanso de los varones de su familia. Sin duda, otra de las imágenes repetidas del imaginario occidental, la mora-bestia es un motor de trabajo por y para el hombre:

Ellas creen que es natural y lógico ahorrar el mayor número de molestias al varón o varones de la casa. Los hombres aquí se sienten mimados y adorados con naturalidad, suponiéndolo la cosa más justa del mundo. Consideran a la mujer como un pedazo de carne sin alma, útil para darles hijos, varones también, y para evitarles los más pesados trabajos. (Aranda 162)

En ningún caso se señala que las mujeres marroquíes que se encuentran en esta situación lo estén por las precarias condiciones socioeconómicas o políticas que pudiera estar atravesando su país, sino que se responsabiliza de esta opresión, únicamente, a los hombres marroquíes y a sus tradiciones supuestamente islámicas. Un islam del que suelen tener un profundo desconocimiento y que asocian con unas costumbres retrógradas y ancestrales. Se dice en una de las obras a examen:

Las mujeres marroquíes tienen mucho aguante, asombra verlas todavía atareadas en el campo en condiciones pésimas, o cargadas de fardos por la carretera mientras el marido va tan campante en su burro. A vosotros no os interesa prescindir de ciertas costumbres ancestrales. (López Sarasúa, ¿Qué buscabais 243)

Manuela Marín advirtió que esa penosa imagen de mujeres extenuadas, cargando haces de leña sobre sus espaldas, fue una constante en la literatura de viajes y, por ello, terminó calando en la imaginación colectiva española (Marín 85). Sin embargo, no sólo fue una constante en la literatura nacional, sino que incluso este retrato rural femenino se propagó en la narrativa europea. George Orwell en la primavera de 1939 se hizo eco de esta realidad cuando visitó Marrakech (Marín 85). Y desde los textos literarios este deplorable icono, esta "oscura existencia» (Flavio 67) de las mujeres autóctonas, pasó a difundirse también bajo el formato de tarjetas postales, cromos y caricaturas convirtiéndose en uno de los símbolos por antonomasia de la situación de inferioridad y atraso del conjunto de la sociedad marroquí por el trato que dispensaba a sus mujeres (Marín 87; Martín Corrales, La imagen del magrebí 106; Martín Corrales, Imágenes del protectorado 384). 
Pero no sólo leña, también la mora-bestia acarrea agua (Cabello, La cazadora 31).

Y, también, ropa sucia. Una vez más, en Alizmur (2000) se subraya que mientras las mujeres trabajan, los hombres perecean de acá para allá:

veían los cuerpos encorvados de las muchachas pasar a lo lejos por los senderos cargando a la espalda los barreños de cinc rebosantes de ropa sucia de toda la familia. (Cabello, Alizmur 144)

Por tanto, este es el personaje femenino autóctono más acostumbrado en las ficciones cuando las tramas se desplazan a zonas rurales, una representación heredera de una sociedad anterior a la actual, en la que los hombres iban con frecuencia a la guerra y las mujeres se ocupaban en su lugar de las tierras. Trabajar en el campo en los textos estudiados -incluso hoy en día y en muchos lugares, incluida España- se consideraba sólo una prolongación del trabajo doméstico. Así que ellas son las que realizan todas las tareas agrícolas, incluidas las más pesadas que tanto sorprenden al ojo extranjero. Cuidan el ganado o hacen ellas mismas las veces de ganado, transportan agua en los cántaros (Villardefrancos 113) y lavan ropa (Charles 81). Son ellas las que arrancan higos de las chumberas (Cabello, La cazadora: 87), las que cuidan las cabras en los aduares (Cabello, Alizmur 147) y las que van a vender esa leña que han cargado sobre sus espaldas (Bacaicoa 87) a los mercados cercanos.

Son tratadas como animales y son narradas como animales: se dice de ellas que son «animales acorralados» (Villardefrancos 8 y 16), «pobres salvajes criaturas» (Villardefrancos 16), que se «acurrucan como un mono» (Martín de la Escalera 145), que tienen «faz simiesca» (Martín de la Escalera 149), rostro de «loro disecado» (Martín de la Escalera 23), mirada de «gallo cruel» (Martín de la Escalera 22), ojos de «bestezuela asustadiza» (Martín de la Escalera 131), o que esos mismos ojos están «anegados por una vaga tristeza animal» (Martín de la Escalera 147). Sus manos son como «garras de cuervo» (Martín de la Escalera 23), sus pies de andar descalzos por el campo y subir y bajar terrenos oblicuos parecen «zarpas», por lo que los dedos de los pies han terminado «formando un puente» (Cabello, Alizmur 47) y es que para estas tramas no son más que «animalillos» por su manera de caminar por los senderos abruptos de las montañas (López Sarasúa, La llamada 234). 
En cuanto a su deambular, son descritas como una «bandada de inquietas palomas» (Martín de la Escalera 207) o un «rebaño anárquico» (Martín de la Escalera 100), misma analogía que usa el personaje de Alfonso Solano para describir un prostíbulo local, en el que asegura que «bien podría recogerse [allí] el ganado por la noche» (Aranda 62). Es más, si a la mora-bestia se le prometía pilones de azúcar, era posible engatusarla para lograr que hiciera lo que se deseara de ella (Villardefrancos 8). Difícil no pensar en este caso en la gratificación o recompensa que se le da al caballo por el trabajo realizado. Después de todo, se las llama potrancas «[e]s una potranca escuálida» (Ibáñez Blanco 56) y se les dice que huelen a «establo, a polvo y a sudor» (Aramburu 38). Incluso se las describe animalizadas para subrayar su sumisión al marido, así lo vemos en Los vencidos (1946): «Aquél natural sometimiento de su Fátima, comparable sólo al de un bello animalejo que busca incesantemente caricias sin saber si molesta» (Viñuelas 47).

Es la «razonadora cabeza europea» (Martín de la Escalera 83) que difunde las ficciones frente aquellos «tipos extraños horrendos, más cerca del mono que del ser humano» (Linares Becerra 286). Así, representando a los marroquíes - no sólo a las mujeres- como animales, animalizándolos, se buscó subrayar la ausencia de razón aunque tuvieran forma humana, porque no tenían libertad y tampoco voluntad. Eran una «civilización retrasada» (Aranda 68) en la que la influencia del darwinismo social desempeñó un papel importante ${ }^{5}$.

Así lo señaló también Rorty, a quien no se le pasó por alto que, junto a la feminización y a la infantilización, la animalización en tanto que se definía así lo «no humano» o lo «inhumano» ha sido una de las formas más usuales de la deshumanización (221).

Animalizar al «otro» marroquí fue, por tanto, desde una representación normativa de la humanidad, una manera de inducir, legitimar y justificar su

5. En el último tercio del siglo XIX, algunos grupos -extrapolando erróneamente la teoría de la evolución de Darwin al campo de lo socio-político-argumentaron el colonialismo y el imperialismo defendiendo que sólo las comunidades con mayor capacidad serían aptas para sobrevivir en un medio particular dado, el resto, estaban condenadas a la supeditación o a la desaparición. Fue de esta manera como «el hombre blanco», en provecho propio, se postuló como el único facultado para «civilizar» a los supuestos pueblos inferiores. Surgió así el darwinismo social como una suerte de máscara del racismo y la xenofobia que se expresó, sobre todo y de forma más violenta, en el antisemitismo nazi de la primera mitad del siglo XX.

Feminismo/s 31, junio 2018, pp. 143-166 
explotación, que pasaba las más de las veces por arrebatarle también su patrimonio. Y, además, eliminaba la responsabilidad ética de aniquilarle, puesto que no era persona. Y, por supuesto, fue un modo de acentuar su otredad como oposición a la humanidad. Una animalidad pergeñada desde los más pequeños detalles, como cuando en una de las novelas se cuenta que la ciudad de Casablanca no tenía todavía puerto y los españoles «desembarcaban a hombros de los marroquíes» (López Sarasúa, La llamada 75). Como vemos, junto con su par femenina, ellos también fueron animales de carga.

No obstante, Césaire en su crítica al discurso colonial, nos ha advertido que tratar al otro como «no humano», como bestia, tiende forzosamente a modificar a aquel que así lo considera, en este caso el colonizador o el portador del discurso axiomático de superioridad. Él mismo se convierte en bestia (Césaire 19). Se ve claro en estas ficciones, por ejemplo, en el reflejo literario de un hecho factual: que las novias españolas pidieran a los soldados durante las guerras contra Marruecos que les trajeran de recuerdo la oreja de un moro (Goytisolo 22; Moreta Lara 43; Madariaga, En el Barranco 39), «[h] ay quien paga a duro cada oreja derecha de mohamed» (Charles 77 ). Todo esto nos vuelve a recordar que si poner fin a una vida no produce ningún tipo de dolor ni peso de conciencia, es que no se trataría de una vida real por lo que, en realidad, no es una violencia que inflija daño (Butler 45-78). La división del mundo entre zonas del ser y zonas del no-ser que llevara a cabo Fanon en Piel negra, máscaras blancas (42-ss) como estrategias para legitimar la desposesión identitaria de la otredad en el discurso colonial queda así registrada en muchas de estas novelas:

Si te portas como espero, te llevaré conmigo a la península cuando me marche... Pasarás tus días acurrucado a mis pies como un falderillo y cuando salga, te sentarás en mi automóvil junto al chófer... ¡Qué felicidad!, ¿verdad? (Estévez de Castro 23)

Con estas palabras se dirige una de las protagonistas de Cita en el paraíso (1941), a un niño de catorce años al que paga unas monedas por acarrear sus paquetes. El «racismo caritativo» del que hablara Memmi es elocuente en este pasaje (134), aunque no tenga la brusquedad cruel y despótica de Burgos, que se refiere a los niños como «animalillos ariscos, medio salvajes [y] feos» (184) o de Viñuelas, quien los llama sin miramientos «adefesios» (29) o «chiquillería simiesca» (22). Sin embargo, está claro que trata al niño 
de la misma manera que en occidente se trata a las mascotas. Hablándole sin dialogar, interpelándole sin esperar respuesta. Es más, con esa forma de relacionarse con él, se consigue, incluso, que el orientalismo de corte científico presente al niño necesitado de ser educado por la racionalidad occidental.

En cuanto a animalizar a la «otra» marroquí, ya desde antiguo se ha venido comparando al conjunto global de las mujeres con los animales. Incluso con la totalidad de la naturaleza, para así asociar -en una oposición binaria nada inocente-al hombre con la cultura y la historia. Hay ejemplos en esta narrativa de este devenir de la mora al espacio ontológico de lo natural: «Zahara era sólo una parte de aquella naturaleza» (Villardefrancos 23) porque entre «las adelfas, Zahara le miraba como una adelfa más» (Villardefrancos 13). Esta es la descripción que hace, sin ir más lejos el médico militar protagonista de El sol nace de madrugada (1953). Con esta comparación de la «otra» marroquí con una flor hace que se reafirme una estructura de valores donde el papel de la mujer local es el de un mero objeto que, además, facilita al hombre la sensación de control y dominio de la naturaleza. Hay muchos más ejemplos de este tipo, aunque a veces se confundan con la trampa del halago: la «otra» marroquí está «nerviosa como un junco» (Villardefrancos 8), es un «capullo de azahar» (Ibáñez Blanco 155), su talle «esbelto y fuerte como una palmera» (Martín de la Escalera 76).

Aristóteles fue de los primeros en relacionar a la mujer con la naturaleza, sobre todo en su aspecto animal, pero, también, la misoginia europea encontró para ello perfecto caldo de cultivo en el judaísmo, en el cristianismo primitivo o en la cultura griega ${ }^{6}$. Así que no es de extrañar que lo veamos también en esta narrativa, donde la descripción de la otredad femenina viene además mediada por lo islámico que, tal y como sostiene Dieste, ha estado también conexo con la animalidad desde la formación del estereotipo en la Península Ibérica (Mateo Dieste, El «moro» entre los primitivos 48). De ello resulta que

6. Recordemos, por ejemplo, el Yambó de las mujeres de Semónides de Amorgos (ss. VII-VI a.C), en el que el poeta vincula a las mujeres con ocho tipos distintos de animales (el perro, el asno, el zorro, el cerdo, la comadreja, el mono, la yegua y la abeja). Los fundamentos de Semónides son mordaces y perversos en prácticamente todos los casos: las mujeres son como los cerdos por su suciedad, como los monos por su fealdad, como los zorros por su astucia, como los perros por su inmoralidad, como los asnos por su cabezonería y lascividad, también con la comadreja por su avidez sexual, etc.

Feminismo/s 31, junio 2018, pp. 143-166 
fueran habituales las caricaturas españolas donde se introdujera al moro en una jaula o se le representara con bozales (Martín Corrales 64). Este conjunto de asociaciones con la naturaleza y la animalidad ayuda a inferir que la mora-bestia no es humana, porque su sociedad de origen la trata como un animal. Despojada de su vida civil, no tiene derechos que puedan ser menoscabados. Su descripción deja a las claras que estamos ante una vida «llena de insospechables sufrimientos» (Flavio 64). Por si fuera poco, a diferencia de los humanos, los animales tampoco pueden ser humillados y eso es justo lo que considera el imaginario social occidental, que oriente humilla a sus mujeres.

Pero, al mismo tiempo, también forma parte del lenguaje del colonizador, nos lo advierte así Fanon:

[E]l lenguaje del colono cuando habla del colonizado, es un lenguaje zoológico. Se alude a los movimientos de reptil del amarillo, a las emanaciones de la ciudad indígena, a las hordas, a la peste, el pulular, el hormigueo, las gesticulaciones. El colono, cuando quiere describir y encontrar la palabra justa se refiere constantemente al bestiario. (Los condenados 33)

Efectivamente, los animales siempre han representado los peligros de las zonas coloniales y, por ello, han estado muy vinculados a su descripción. Pratt, por ejemplo, nos recuerda la costumbre de los navegantes que llenaban los espacios en blanco de los mapas con dibujos e iconos representativos de los peligros que consideraban locales como las «amazonas en el Río Amazonas, caníbales en el Caribe, camellos en el Sáhara, elefantes en la India [...]» (70). Así, no tiene tanto que ver con el tratamiento que se supone reciben las mujeres en Marruecos, sino también con el orden simbólico de la mirada que observa y que tiende a vincular la otredad con procesos de animalización.

Dicho esto, también hay que reconocer, como indica José María Perceval, que «no todos los apelativos animalizadores pueden ser considerados insultantes» (260) pero, sin lugar a dudas, siempre denigra emplear figuras retóricas que, sobre la base de fingidas semejanzas, desdibujan la línea que separa al ser que piensa del que no lo hace, el ser humano, de la bestia. En esta línea, los ejemplos son muchísimos más. La «otra» marroquí -no sólo el personaje representado como mora-bestia- es descrita, asociada y comparada insistentemente con animales en una selección léxica (Martín-Márquez 165) nada inocente: «¡Tienes aptitudes de hormiga o de esclava!» (Ibáñez Blanco 190) le dicen a la protagonista de una de las novelas; «tú eres una gacela con

Feminismo/s 31, junio 2018, pp. 143-166 
un panal de miel por corazón» (Ibáñez Blanco 27) se dice en otra; incluso se asegura que a «las mujeres hay que tratarlas como a las mulas» (Ibáñez Blanco 257) o que se les da de comer las sobras de la comida de los hombres (Aramburu 60), justo igual que si fueran animales.

Así, podemos concluir que en la mora-bestia se fusionan dos realidades que, excediendo los parámetros de la naturaleza, mezclan dos reinos: el humano y el animal. Ha sido Michel Foucault, entre otros, quien ha mantenido que en esta composición mixta se halla una de las formas de concebir la monstruosidad ${ }^{7}$. Así, afirma que ser un monstruo es, en este sentido, la «transgresión de los límites naturales, transgresión de las clasificaciones» (Foucault 64). Una manera de perturbar el orden que ha hecho que lo femenino y lo monstruoso se vinculen desde antiguo, de ahí que la mitología clásica y la literatura nos brinden tantos ejemplos de monstruos femeninos mitad mujer, mitad animal como Medusa o la bella Melusina. Probablemente, consecuencia directa también del interés que suscita dentro de los estudios feministas, corrientes que, del mismo modo, han visto en la hibridez la causa de la monstruosidad (Balza, Cuerpos biopoliticos 239; Balza, Hacia un feminismo monstruoso 90). O lo abyecto -por llamarlo como Kristeva- que también rompe los límites, las fronteras de la subjetividad y que hace que la noción de identidad se desvanezca junto con los contornos corporales.

Los monstruos en la literatura han sido estudiados con detenimiento, pero debemos ser conscientes de que no son un símbolo unívoco. Cada época, cada pueblo, clase o grupo social tiene sus propios tipos de monstruos porque éstos, como partes de los sistemas de dominación vigentes, son contextuales y metaestables.

Se trata, desde luego, de una forma de asegurar la supervivencia frente al monstruo y no perder el ejercicio hegemónico del poder. A causa de ello, podría dedicarse un trabajo de investigación por entero a los esquemas de valores y las estructuras sociales en torno a la representación del «otro» colonial como monstruo en esta narrativa durante el pasado siglo XX. Un

7. Michel Foucault dictó un curso en 1975 titulado Los anormales en el Còllege de France. En este curso explicó que había tres modos de concebir la monstruosidad en el ser humano: el hombre como bestia en la Edad Media (mezcla de humano y animal), los siameses en el Renacimiento (mezcla de individuos) y los hermafroditas en la Época Clásica (mezcla de sexos).

Feminismo/s 31, junio 2018, pp. 143-166 
monstruo que, además, está en permanente movimiento, debido a los cambiantes prejuicios culturales que han ido siendo dominantes en cada momento y que, desafortunadamente, han determinado la existencia de desigualdades entre un grupo y otro. En efecto, es un monstruo -sobre todo en su versión femenina- fruto de las articulaciones complejas de dominación y resistencia pero, sobre todo, de las ansiedades de aquél que lo observa ${ }^{8}$. Las descripciones polarizantes recurrentes y metáforas duales, hemos comprobado, devuelven a la otredad marroquí la peor parte, como proyección desplazada del «yo». Bajo esta óptica, lo marroquí fue monstruo porque se alejaba de lo español, en tanto en estas fuentes lo español era la norma establecida y ser monstruo consistía básicamente en eso, en no cumplir las leyes, en desobedecer la norma. Pero, además, fue un monstruo esperado en la medida que el encuentro con monstruos formaba parte de los acontecimientos que aguardan en un viaje a tierras extrañas.

Las autoras de los relatos analizados, convencidas de su superioridad, estaban seguras de no compartir el mismo canon hegemónico ni en su aspecto ni en su conducta moral, social, sexual, política o cultural con la otredad femenina marroquí: un doble maldito que, en ese sentido, se trató más de un discurso occidental que giraba sobre sí mismo, que sobre el «otro». Se subrayó con las estrategias representacionales en torno a la mora-bestia que la realidad de las mujeres en España, en Europa, era claramente opuesta. Una española asegura que «Nosotras ya hace mucho que hemos aprendido a no aceptar con tanta resignación esos designios» (López Sarasúa, ¿Qué buscabais 244), de hecho, cuando el personaje de Redia, la protagonista de Noche nupcial sin novia (1956) expresa su deseo de ser libre y no soportar el yugo masculino, le dicen que debió haber nacido europea (Ibáñez Blanco 14). Ser mora, por tanto, es la peor de las desdichas, «quisiera ser paloma antes que mora» (Linares Becerra 304).

El análisis de los monstruos permite conocer la realidad social de la literatura que los creó. Con todo, la figura del monstruo permitió concebir una identidad, que por híbrida, fue variable, plural y que, aunque pareciera que en un principio fue sólo un mecanismo excluyente que desplazó a la «otra» marroquí a los márgenes de lo inapropiado, fue mucho más que eso. Lo que

8. Monstruo proviene del latín monstrare, 'mostrar'.

Feminismo/s 31, junio 2018, pp. 143-166 
consiguieron estas ficciones, desde esta perspectiva, fue poner en cuestión esos mismos márgenes que, por supuesto, en la actualidad pueden ser re-definidos y re-valorizados no sólo de modo literario.

En efecto, si analizamos de manera sistemática los 59 textos que componen el conjunto de fuentes primarias de este trabajo comprobaremos que el único criterio para que la «otra» marroquí sea considerada un monstruo es no parecerse al autorretrato que las mujeres españolas tenían de sí mismas, la norma, lo común. Por tanto, cualquier tipo de mora es un monstruo porque se proyectan en ella las diferencias de la mujer española, su contrapunto y su reverso, evidenciando de esta forma que lo «auténticamente monstruoso es descubrir lo monstruoso en el seno del ser humano» (Cortés 30). Justo a esa conclusión fue a la que llegó Magrit Shildrick al estudiar la relación entre la mujer y lo monstruoso, que esa realidad que se rechaza se halla, en verdad, en el interior del cuerpo normativo (Embodying the Monster; The Disabled Body). Algo que en el contexto de estas ficciones podría explicar por qué un simple cambio de ropa -de la occidental a la supuestamente islámica- permitía a la mujer española convertirse en mora, al dinamitar las categorías binarias tradicionales y devolvernos, de esta manera, una figura híbrida, resultado de la mescolanza entre lo español y lo marroquí. En este caso, como Braidotti nos advierte, los componentes principales del cuerpo monstruoso han sido el género y la etnia-raza (Braidotti 300).

Las moras son violentas, traicioneras, fanáticas, primitivas y ambiciosas porque se sitúan fuera de las fronteras de lo aceptado, son lo excedido. $\mathrm{Y}$, por supuesto, como monstruos producen miedo, pero también generan tranquilidad -el monstruo como catarsis- dentro de la ambivalencia del discurso orientalista que insiste en el no somos como ellos, somos superiores. La mora-bestia fue un monstruo porque es tratada como si fuera un animal, es de hecho medio animal y ésta ha sido, ya hemos visto, una de las formas más frecuentes de categorizar a los monstruos por su combinación con otros seres o figuras. Así, de todo ello resulta que sobre la «otra» marroquí recaé el estigma del monstruo, cargado semánticamente de valores negativos. Sin embargo, incluso así, cumple una función:

Y es que la fealdad del monstruo resalta nuestra belleza; y por eso lo necesitamos, porque su deformidad confirma nuestra aparente normalidad; y su perversión, nuestra bondad. (Calleja 13)

Feminismo/s 31, junio 2018, pp. 143-166 
Algunas investigadoras de cuentos de hadas, como María Tatar, han afirmado que la misión de los monstruos y las criaturas terribles en esos relatos mágicos es la de mantener idealizada la imagen de los padres (Tatar 31). Puede aplicarse a este género de colonias cambiando sólo de quién se quiere mantener la imagen idealizada. En estas ficciones los monstruos reconcilian al público lector con lo español y, por medio del mecanismo coercitivo expuesto, se consigue salvaguardar lo patrio de toda crítica y que, en ningún caso, se quiera identificar con la otredad.

Y cerca de la animalización, y de sus procesos varios de monstruosificación, está la cosificación de la mora-bestia como un mecanismo más de degradación social. Con ella se persigue acentuar su abandono y vulnerabilidad. Pero la cosificación se lleva a cabo no sólo por los personajes marroquíes, sino también por los españoles, veamos, una pareja de ellos se detiene delante de la «otra» marroquí y se preguntan entre sí, como si ella no existiera, «¿De qué clase será?» (Rivas 38).

Esta cuestión, lanzada casi al aire en un clima cultural donde las mujeres son tratadas como objetos por los principios que le suponen propios a su religión, no sorprende en absoluto. La mora-bestia en esas ficciones puede ser comprada, vendida, regalada y hasta robada por camelleros como sucede en El sol nace de madrugada (1953). Pero hay más ejemplos: «Mi señora me quiere regalar» (Jadraque 61), o son «mujeres para regalo del Sultán» (Villardefrancos 7). Las escritoras del corpus las definen como «objetos con amo» (Linares Becerra 286) o de «su señor» (Linares Becerra 300). Y es que la propia mora-bestia se considera objeto poseído, de ahí que sus amigas le aconsejen antes de la boda que su marido «es el dueño y tú la esclava. Obedécele» (Aramburu 98); porque «el hombre es dueño de sí mismo; la mujer esclava del marido...» (Ibáñez Blanco 213) y ella hable entonces de él como de «mi dueño» (Ibáñez Blanco 44) o «idel amo!» (Estévez de Castro 142).

En muchas ocasiones, en los mercados de esclavos que imaginan para sus tramas, se pueden observar con «ojos críticos y tasadores» mujeres para luego adquirirlas por no más de «quince duros en plata» (Ibáñez Blanco 56). $\mathrm{Y}$ aunque lo habitual es que la compra y venta de seres humanos se realice con personas negras, no en muy pocas ocasiones aparecen también las esclavas blancas. Algunas autoras, incluso, señalan que podrían ser confundidas con mujeres europeas (Linares Becerra 303). Muchas veces con esa compra

Feminismo/s 31, junio 2018, pp. 143-166 
se quiere encerrar a las mujeres en el harén como el del hombre que quiso comprar a la bailarina de un espectáculo en Marrakech con «tal de poseerla» (López Sarasúa, ¿Qué buscabais 146) pero, las más de las ocasiones serán utilizadas en las tareas del campo o las labores domésticas como bestias de carga. Veamos el aparente comentario inofensivo que se hace en la novela ¡Demasiado tarde! (1956) de unos niños españoles que vivían en Marruecos:

Habían nacido en Tánger, y estaban familiarizados con los moros; pero jamás tuvieron en su casa ninguno como sirviente y como los niños son amantes de la novedad, aquello les hizo ilusión. (Martel 14)

En este sentido, el nuevo sirviente hace ilusión como si fuera una mascota. Hay muchos ejemplos en las ficciones en esta línea, dice una musulmana a una mujer española para que la tomara en su casa: « ¿No tienes perro, señora? Déjame en su garita. Yo seré tu perro, tu esclava» (Nonell 234).

Sólo las familias pudientes tenían esclavas a las que, la mayor parte de las veces, se trataba peor que animales. Por ejemplo, cortándoles la lengua, literalmente, si hablaban demasiado (López Sarasúa, ¿Qué buscabais 166). Había mujeres que, aun no siendo esclavas, eran tratadas como si lo fueran, como la mora-bestia. De ahí que, en ocasiones, la compra y venta de mujeres sea más sutil dado que el pago es la propia dote que se recibe al contraer matrimonio. Dice la protagonista de Noche nupcial sin novia (1956):

Sin embargo, vosotros, la peor parte se la hacéis sufrir a la más sensible; la vejáis, ¿Pero y su espíritu, y su corazón, eso no cuenta por el hecho de nacer musulmana? (Ibáñez Blanco 158-9)

La verdad es que Redia, el personaje de esta novela, es especialmente combativo con lo que se supone que son las tradiciones marroquíes, por lo que manifiesta de manera insistente que está harta de sentirse como «mercancía» en todas estas transacciones donde, desde luego, la mujer no opina (Ibáñez Blanco 11 y 67). También se llama a sí misma, presa del dolor, «carnada» (Ibáñez Blanco 196).

Finalmente, lo último en lo que se insiste en el retrato de la mora-bestia es su precariedad económica. Se señala que todas ellas son pobres, que nunca han ido a la escuela (López Sarasúa, La llamada 76) y, de las más jóvenes, incluso que han tenido que dejar los estudios para cuidar de sus hermanos más pequeños, del hogar o ayudar en las labores del campo. 
Halima había abandonado la escuela siendo todavía muy niña [...] sus padres ¡ah, su mala fortuna y las bocas que debían alimentar!, la emplearon en la residencia del capitán Romero, donde secundaría a la fatma en las tareas de la casa. (López Sarasúa, La llamada 190)

Peor retrato hace Concha López Sarasúa de Naima, la protagonista de uno de sus relatos incluidos en A vuelo de pájaro sobre Marruecos (1988). La narradora describe a una campesina con la que coincidió en un tren destino a Tánger. Le llama la atención su atuendo, sus rasgos y el cesto de mimbre que lleva consigo cubierto de trapos y en el que «descubrió la cabeza de una gallina» (López Sarasúa, A vuelo 140). Y aunque en un principio la narradora comenta que todos en el tren se rieron ante este hecho -incluso la propia campesinapronto el ambiente se inundó de un aire más abatido. Naima refiere los avatares de una vida difícil, donde había tenido nada menos que diez hijos para satisfacer a su marido y donde era fácil percibir en sus gestos «la resignación con que afronta los avatares de una vida difícil y dura» (López Sarasúa, A vuelo 140). Las dificultades económicas de esta mora son visibles al ver cómo reacciona al llegar el revisor:

De improviso se abrió la puerta del vagón y apareció el revisor. Posiblemente creyera Naima que la baraka la acompañaría durante el trayecto, pero no había sido así. La vi desesperanzada hablar con el empleado, lamentarse... Al fin extrajo de la faltriquera un pañuelo sucio, y después de desatar el nudo donde guardaba el dinero empezó a sacar a la luz unos billetes de diez dírhams más mugrientos incluso que el envoltorio. Los desdoblaba con mansedumbre, se los iba entregando tan lentamente como si se desprendiese del más valioso de los tesoros. Treinta dírhams y medio que parecían arrancárselos del fondo del alma. Recogió el papel que le tendía el revisor y se quedó pensativa, la cabeza apoyada en la frente como si rumiara su desdicha. (López Sarasúa, A vuelo 140-1)

Precariedad económica. Trabajo. Dura vida en el campo. Muchos hijos. De algún modo, este corto relato condensa y ejemplifica todo lo que se ha señalado con anterioridad en torno a la representación de la mora campesina -la mora-bestia de este trabajo de investigación- subrayando su situación de dependencia y el injusto contexto en el que las ficciones estudiadas consideran que se desarrolla su vida. 


\section{CONCLUSIONES}

Las escritoras de estas novelas y relatos del pasado siglo XX, visto lo anterior, ayudaron con sus textos a dejar constancia de lo mal que trataba oriente -su religión y sus hombres- a las mujeres marroquíes «eternas marginadas», y en ningún caso achacaron esta situación a las precarias condiciones socioeconómicas que pudiera estar atravesando el país o los distintos escenarios políticos que hubieran podido influir igual o más en su devenir histórico. El acercamiento que han llevado a cabo las escritoras, por tanto, carece del rigor que aportaría una ciencia etnológica crítica dado que, en prácticamente ningún caso, han tenido un deseo expreso de conocer la realidad factual de la sociedad que describían. Es el discurso de la superioridad occidental que insiste en dibujar el retrato de una sociedad que devalúa, maltrata, veja y hasta deshumaniza a sus mujeres para que se empatice de esta manera con la causa colonial, al menos hasta 1956, y así motivar políticas coloniales en aras del progreso y del desarrollo. De ahí que, en líneas generales, todas las autoras hagan un juicio positivo del colonialismo y no sean frecuentes las críticas a la presencia española en el norte de África. Tras la independencia de Marruecos, los textos se han amoldado a los nuevos tiempos, sin duda, pero sigue persistiendo este posicionamiento de superioridad como rasgo de lo que se ha denominado «imperialismo», «neocolonialismo»o «fase hegemónica». Un control de las antiguas colonias que, a pesar de no ser tan directo como antaño, sigue sometiendo a la otredad -otrora colonial- a los dictámenes políticos, económicos, lingüísticos y, sobre todo, culturales de las grandes potencias y es que, como advierte Liliana Suárez Navaz, el colonialismo no es ni mucho menos «un periodo histórico superado, un fósil inerme» (31).

En consecuencia, los relatos y novelas insisten -antes y después de la independencia del país- en que sólo occidente valora a las mujeres, incluidas las marroquíes, y está dispuesto a liberarlas cuan damiselas en apuros en una suerte de pseudofeminismo libertario que funcionó únicamente como coartada. La mora-bestia extremadamente vulnerable, cautiva de sus tradiciones e indefensa ante los varones de su familia y la cultura de su país, tuvo, así, una motivación perversa.

Las postdatas históricas, además, ponen al descubierto el discurso pragmático y utilitarista de este orientalismo que buscó, incluso, justificar el dominio 
colonial. Por un lado, y a pesar de que las autoras de las fuentes estudiadas no suelan hacer esa analogía, hubo mujeres en la España rural, sobre todo durante la primera mitad del siglo XX, que vivían o malvivían igual que la mora-bestia $a^{9}$. Algo que ya habían denunciado otras voces investigadoras como, por ejemplo, Germaine Tillion en su ensayo, ya clásico, L'harem et les cousins (1966) y que demostraba que la opresión femenina que se denunciaba para con las mujeres del Magreb era, en realidad, la misma situación compartida de la mujer en toda el área mediterránea. Y, por otro lado, porque las mujeres marroquíes siguieron cargando leña y uncidas al arado después incluso de la ocupación colonial española (Rosillo 52), lo cual viene a evidenciar que la preocupación por la mora-bestia era una preocupación interesada y cómplice de las políticas coloniales de la España de primera mitad del siglo XX. El discurso de su sometimiento no luchaba en pos de una igualdad de género objetiva, sino que buscaba insistir en el retrato de una sociedad degradada, bárbara, para que, a través de la excusa salvífica de las mujeres, se pudiera acceder a los recursos de aquellas tierras. Una técnica ésta bastante habitual en escenarios coloniales y que el propio Fanon había denunciado en otros contextos, como, por ejemplo, Argelia (Sociología de una revolución, 21-ss).

En definitiva, lo que está claro es que esta narrativa está llena de pequeños argumentos que motivaron y hasta, incluso en algunos casos, justificaron la intervención colonial en Marruecos o la superioridad de la metrópoli cuando la época de colonias ya había pasado de facto. En ambos casos, las mujeres fueron solamente la excusa. Y, si bien hay que tener en cuenta que todas estas fuentes se presentan como ficcion, la repetición constante de un determinado tipo de personaje dificulta sobremanera que el público lector pueda llegar a pensar que la realidad sea diferente. Así, esta narrativa se convierte en una forma de poder que se apropia de la «otra» marroquí, a través de un relato

9. Merece la pena ver cómo denuncia la misma situación de opresión en España el interventor Emilio Blanco Izaga: «Yo me atrevería a afirmar, que la mujer rifeña, con una jornada de trabajo semejante o inferior a la vascongada de caserío, donde se deslizó mi infancia, encuentra en los mercados, bodas, aguadas, ermitas, etc...., alicientes iguales sino mayores por su menor rigidez de costumbre, y sin embargo, que yo sepa, a nadie se le ha ocurrido gimotear por la libertad de las vascongadas [...], sino al contrario, proclamar sus virtudes considerándolas ejemplares. ¿Por qué medir con diferentes raseros análogos efectos?». (Blanco Izaga apud. Moga Romero 295-6).

Feminismo/s 31, junio 2018, pp. 143-166 
basado en simplificaciones y generalizaciones. El propósito principal de este trabajo ha sido, en este sentido, poner al descubierto esas estrategias representacionales y sus intereses encubiertos.

\section{REFERENCIAS BIBLIOGRÁFICAS}

Aramburu, Rosa de. Ojos largos. Madrid: Editorial Española, 1937.

Aranda, Rosa María. Tebib. Zaragoza: Artes Gráficas E. Bermejo Casañal, 1945.

Astray Reguera, Margarita. «Pasión de moro». Los contemporáneos, 879, Madrid, 1925.

Bacaicoa, Dora. Zohora la negra y otros cuentos. Tetuán: Colección Manantial, 1955.

Balza, Isabel. «Hacia un feminismo monstruoso: sobre cuerpo político y sujeto vulnerable». Las lesbianas (no) somos mujeres. En torno a Monique Wittig. Ed. Beatriz Suárez Briones. Barcelona: Icaria, 2013. 85-115.

Balza, Isabel. «Cuerpos biopolíticos: harpías y hechiceras. Sobre monstruos femeninos y mujeres monstruosas». El cuerpo en mente. Versiones del ser desde el pensamiento contemporáneo. Eds. Mireia Calafell y Aina Pérez. Barcelona: Editorial UOC, 2011. 237-245.

Braidotti, Rosi «Signs of Wonder and Traces of Doubt: On Teratology and Embodied Differences». Feminist Theory and the Body. Eds. Janet Price \& Magrit Shildrick, London and New York: Routledge, 1999. 290-301.

Burgos, Carmen de. «En la guerra». La flor de la playa y otras novelas cortas. Ed. Concepción Núñez Rey. Madrid: Castalia, 1989. 163-218.

Butler, Judith. «Violencia, duelo, política». Vida precaria: El poder del duelo y la violencia. Buenos Aires: Paidós, 2006. 45-78.

Cabello, Encarna. Alizmur. Barcelona: Meteora, 2000.

Calleja, Seve. Desdichados monstruos. La imagen deformante y grotesca de «el otro». Madrid: Ediciones de la Torre, 2005.

Carrasco González, Antonio. Historia de la novela colonial hispanoafricana. Madrid: Sial, 2009.

Césaire, Aimè. Discurso sobre el colonialismo. Madrid: Akal, 2006.

Charles, María. Etxezarra. Barcelona: Anagrama, 1993.

Cortés, José Miguel G. Orden y caos. Un estudio cultural sobre lo monstruoso en el arte. Barcelona: Anagrama, 1997.

Culler, Jonathan. Breve introducción a la teoría literaria. Madrid: Austral, 2014. Estévez de Castro, Mari Paz. El convoy de la muerte. Pueyo: Madrid, 1954. 
Fanon, Frantz. Los condenados de la tierra. Navarra: Txalaparta, 2014.

-. Piel negra, máscaras blancas. Madrid: Akal, 2009.

—. Sociología de una revolución. México: Ediciones Era, 1976.

Flavio, Regina. Alma de Marruecos, Barcelona-Sevilla: Ediciones Betis, 1938.

Foucault, Michel. Los anormales. Madrid, Akal, 2001.

Goytisolo, Juan. «Cara y cruz del moro en nuestra literatura». Crónicas Sarracinas. Barcelona: Seix Barral, 1989. 7-25.

Hall, Stuart. Questions of Cultural Identity. Sage: London, 1996.

-. «The Two Paradigms». Media, Culture and Society 2 (1980). London: Hutchinson, 42-61.

Ibáñez Blanco, Blanca. Noche nupcial sin novia. B. I. B. Granada: Imprenta José María Ventura Hita, 1956.

Jadraque, María Teresa. Halima. Madrid-Cádiz: Escélicer, 1954.

Linares Becerra, Concha. Muchachas sin besos, Madrid: Cunillera, 1971.

López García, David. El blocao y el oriente: una introducción al estudio de la narrativa del siglo XX de tema marroquí. Madrid: Turner, 1994.

López Sarasúa, Concha. ¿Qué buscabais en Marrakech? Alicante: Cálamo, 2002.

—. La llamada del almuédano, Alicante: Cálamo, 2000.

Madariaga, María Rosa de. «El protectorado español en Marruecos: algunos rasgos distintivos y su proyección en el presente». Anales de Historia Contemporánea 23 (2007): 171-182.

-. En el Barranco del Lobo... Las guerras de Marruecos. Madrid: Alianza, 2006.

Marín, Manuela. «Mujeres, burros y cargas de leña: imágenes de la opresión en la literatura española de viajes sobre Marruecos». El Protectorado español en Marruecos. Gestión colonial e identidades. Eds. Fernando Rodríguez Mediano y Helena de Felipe. Madrid: Consejo Superior de Investigaciones Científicas, Madrid, 2002. 85-110.

Martel, Carmen. ¡Demasiado tarde! Madrid: Pueyo, 1956.

Martín Corrales, Eloy. «Imágenes del protectorado de Marruecos en la pintura, el grabado, el dibujo, la fotografía y el cine». España en Marruecos (1912-1956). Discurso geográficos e intervención territorial. Eds. Joan Nogué y José Luis Villanova. Lléida: Editorial Milenio, 1999, 375-399.

Martín Corrales, Eloy. La imagen del magrebí en España: una perspectiva histórica siglos XVI-XX, Barcelona: Bellaterra, 2002.

Martín de la Escalera, Carmen. Fatma. Cuentos de mujeres marroquies. Madrid: Publicaciones África. Instituto de Estudios Políticos, 1945. 
Martin-Márquez, Susan. Desorientaciones. El colonialismo español en África y la performance de identidad. Barcelona: Bellaterra, 2011.

Mateo Dieste, Josep Lluís. El «moro» entre los primitivos. El caso del Protectorado español en Marruecos. Barcelona: Fundación La Caixa, 1997.

-. La hermandad hispano-marroquí: política y religión bajo el protectorado español en Marruecos (1912-1956). Barcelona: Bellaterra, 2003.

Memmi, Albert. Retrato del colonizado precedido por retrato del colonizador. Madrid: Edicusa, 1971.

Moga Romero, Vicente. El Rif de Emilio Blanco Izaga. Uned-Melilla: Bellaterra, 2009.

Moi, Toril. Teoría literaria feminista. Madrid: Cátedra, 1988.

Moreta-Lara, Miguel Ángel. «La imagen del moro en la literatura de la guerra civil española». La imagen del moro y otros ensayos marruecos. Málaga: Aljaima, 2005. 19-55.

Nonell, Carmen. Zoco grande, Madrid: Colenda, 1956.

Perceval, José María. Todos son uno. Arquetipos, xenofobia y racismo. La imagen del morisco en la Monarquía Española durante los siglos XVI y XVII. Almería: Estudios Almerienses, 1997.

Pratt, Mary Louise. Ojos imperiales. Literatura de viajes y transculturación. México: Fondo Instituto de Cultura Económica, 2010.

Rivas, Josefina María. Noches de Tánger. Barcelona: Bruguera, 1949.

Romero Morales, Yasmina. «La otredad femenina en la narrativa colonial escrita por mujeres: Spivak y los feminismos postcoloniales». Cuestiones de género: de la igualdad y la diferencia 12 (2017): 39-53.

—. «Nombrarlas 'moras': personajes femeninos hechos de otredad en la literatura española del siglo XX». Ogigia. Revista Electrónica de Estudios Hispánicos 23 (2018): 29-48.

Rorty, Richard. Verdad y progreso. Escritos filosóficos 3. Barcelona: Paidós, 2000. Rosillo, Rafael. «Mirando al Marruecos español». Revista Geográfica Española 5 (1940): 49-62.

Said, Edward. Orientalism. New York, Pantheon Book, 1978.

Shildrick, Margrit. «The Disabled Body, Genealogy and Undecidability». Cultural Studies 19 (2005): 775-770.

-. Embodying the Monster. Encounters with the Vulnerable Self. London: Sage, 2002. 
Stepan, Nancy. «Biological Degeneration: Races and Proper Places». Degeneration: The Dark Side of Progress. Eds. J. Edwards Chamberlin \& Sander L. Gilman. New York: Columbia University Press, 1985. 97-120.

Spivak, Gayatri Ch. "Can the Subaltern Speak?». Marxism and Interpretation of Culture. Ed. Cary Nelson. Urbana-Chicago: University of Illinois Press, 1988. Suárez Navaz, Liliana. «Colonialismo, gobernabilidad y feminismos postcoloniales». Descolonizando el feminismo. Teorías y practices desde los márgenes. Eds. Liliana Suárez Navaz y Rosalva Aída Hernández. Madrid: Cátedra, 2008. 31-73.

Tatar, Maria. Off with Their Heads! Fairy Tales and the Culture of Childhood. New Jersey: Princeton University Press, 1993.

Tillion, Germaine. La condición de la mujer en el área mediterránea. Barcelona: Península, 1993.

Villardefrancos, Marisa. El sol nace de madrugada. Madrid: Biblioteca de Chicas, 1953.

Viñuelas, María. Los vencidos. Madrid: Aguilar, 1946. 